\title{
Switching control of self-excited induction generator under steady state conditions
}

\author{
Anjali Garg \\ Department of Electrical, \\ Electronics and \\ Communication Engineering, \\ ITM University, \\ Gurgaon, India
}

\author{
K.S. Sandhu \\ Department of Electrical \\ Engineering, National Institute \\ of Technology, \\ Kurukshetra, India
}

\author{
L.M. Saini \\ Department of Electrical \\ Engineering, National Institute \\ of Technology, \\ Kurukshetra, India
}

\begin{abstract}
This paper presents a Matlab based simulation model to regulate the terminal voltage and frequency of three phase self-excited induction generator using switching control . A new block in Matlab has been developed for steady state analysis of three phase self-excited induction generator wherein the output voltage and frequency of generator remains constant irrespective of changes in consumer load. The model involves a switching system comprising of number of suitable resistive elements connected in parallel to the load. Simulated results on a test machine are found to be well within the tolerable limits.
\end{abstract}

\section{General Terms}

Renewable energy source, power generation, Wind, simulation, voltage and frequency control, Dump load

\section{Keywords}

Self-excited induction generator, Switching system, Matlab, Wind energy.

\section{NOMENCLATURE}

\begin{tabular}{|c|c|}
\hline$R_{1} \& R_{2}$ & : stator and rotor resistances per phase respectively \\
\hline$x_{1} \& x_{2}$ & $\begin{array}{l}\text { : stator and rotor leakage reactance per phase } \\
\text { respectively referred to stator. }\end{array}$ \\
\hline $\mathrm{R}$ & : resistive load per phase \\
\hline$X_{m}$ & : magnetizing reactance per phase \\
\hline C & : exciting capacitance per phase \\
\hline$E_{1}$ & : air gap voltage per phase \\
\hline V & : load voltage per phase \\
\hline a & : ratio of generated frequency to rated frequency \\
\hline b & : ratio of actual rotor speed to synchronous \\
\hline & speed corresponding to rated frequency \\
\hline Ns & : synchronous speed \\
\hline $\mathrm{N}$ & : rotor speed \\
\hline$P_{G}$ & : total generated power \\
\hline$P_{c}$ & : total consumer power \\
\hline$P_{D}$ & : total dump load power \\
\hline IL & : load current \\
\hline ID & :dump current \\
\hline
\end{tabular}

\section{INTRODUCTION}

Due to rapid decrease in fossil fuels and increase in global warming due to the use of fossil fuels, the attention is diverting towards the importance of locally available natural resources which not only will provide an alternative energy source with less cost but will also be helpful in maintaining a pure and healthy atmosphere. Out of all renewable energy sources present, wind energy seems to be prominent and quite promising for electric power generation. Besides clean and pollution free energy resource, it has been found that as compared to cost of wind energy generation, cost of fossil fuels are rising at a much faster rate and with time it will be non-affordable for the common man to use fossil fuels.

Maintenance and operational simplicity, self-protection against faults, brush less and rugged construction, good dynamic response are some of the advantageous features of Induction generators. The capability to generate power at varying speed is the feature of induction generator which helps it to operate in self-exited/isolated mode to supply far flung and remote areas where extension of grid is not economically feasible; in conjunction with the synchronous generator to fulfill the increased local power requirement. The main bottleneck of using self excited induction generators (SEIG) is reactive power consumption and poor voltage regulation. Some of the researchers tried to analyze the steady state behavior of self-excited induction generators [1-9] using different methods and logic but variation of terminal voltage and frequency is found to be the major problem associated with such machines.

Induction machine generates power when enough excitation is provided and its rotor is driven at a speed above synchronous speed. Some major issues related to the excitation capacitance requirements have been discussed in [10-11].

Use of electronic load controller (ELC) with SEIG has already been reported in the literature [12-14]. ELC used to control the terminal voltage of a SEIG consists of uncontrolled rectifier, a filtering capacitor, a controller and dump load.

In this paper, a switching system is designed as an induction generator controller (IGC) for SEIG. This switching system will act like a dump load which is connected in parallel with the consumer load in such a way that the effective loading on the machine is independent of consumer load. Simulated results for terminal voltage and frequency as obtained are found to be well within the tolerable limits for any change in consumer load.

\section{SYSTEM DESCRIPTION}

A schematic representation of the proposed system is shown in Figure 1. It consists of three phase star connected squirrel cage induction motor working as self-excited induction 
generator when driven by a constant speed prime mover with suitable value of excitation capacitance across its stator terminals. Excitation capacitors are selected in such a manner that it result in rated terminal voltage and frequency at the rated load.

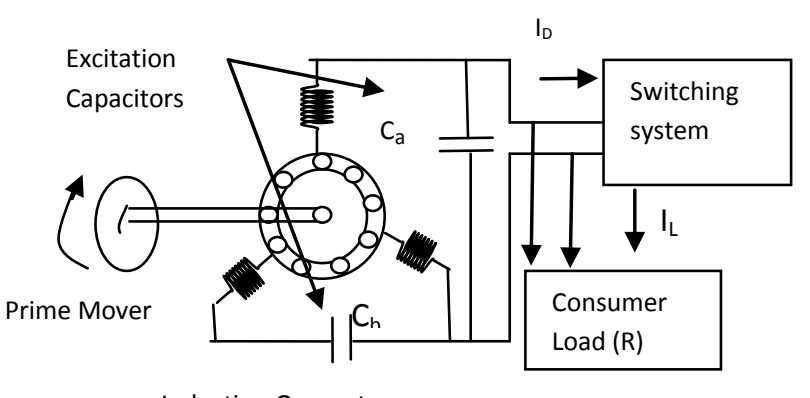

Induction Generator

Fig.1: Schematic representation of self-excited induction generator

The circuit is simulated in Matlab/Simulink environment as shown in Figure 2. The induction generator has been modeled as a new embedded block in Simulink. It represents steady state model of self-excited induction generator. The block has inputs as load resistance, dump resistance, excitation capacitance value and synchronous speed and output as load resistance, load current, contribution of load and dump resistance, dump current and terminal voltage.

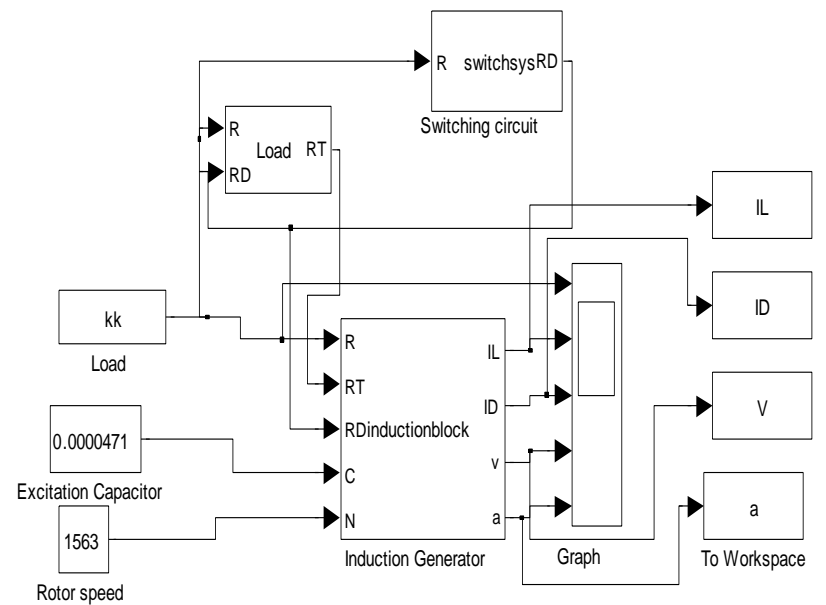

Fig. 2: Schematic representation of proposed system in Matlab/Simulink

\section{STEADY STATE OPERATION AND EQUILIBRIUM EQUATIONS}

The characteristics for steady-state operation of SEIG can be derived using conventional equivalent circuit of induction machine, with the exception that the shunt branch contains only the magnetizing reactance $\mathrm{Xm}$. In the presence of dump circuit, this conventional equivalent circuit representation may be modified as shown in Figure 3 where all the parameters are referred to rated frequency, assuming that all the inductive reactances are proportional to the frequency.

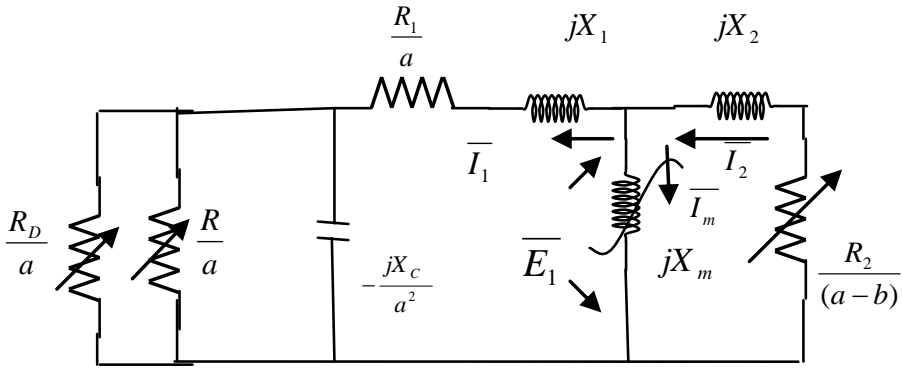

Fig. 3: Per phase equivalent circuit for steady state operation of SEIG using dump resistance

The circuit is further transformed into Figure 4

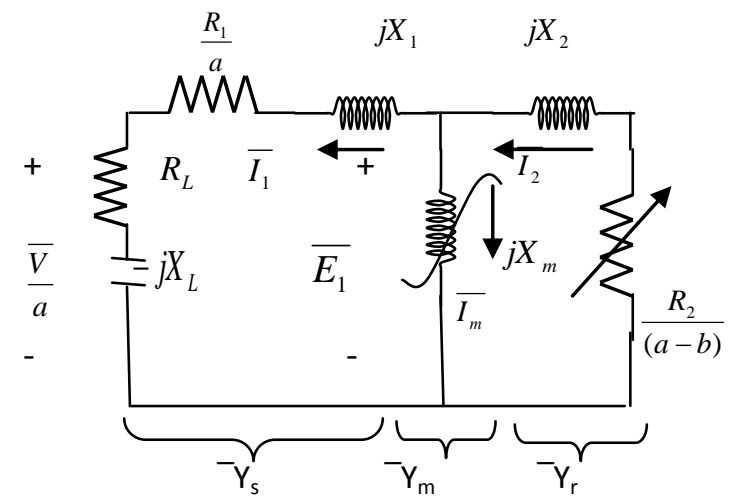

Fig. 4: Modified per phase equivalent network of SEIG

Where $R_{L}-j X_{L}$ is the impedance due to contribution of $\frac{R}{a}, \frac{R_{D}}{a}$ and $-\frac{j X_{C}}{a^{2}}$. The quantities $R_{L}$ and $X_{L}$ are given as: $R_{L}=\frac{R_{T} X_{C}^{2}}{a\left(a^{2} R^{2}+X_{C}^{2}\right)}{ }^{\prime} X_{L}=\frac{R_{T}^{2} X_{C}}{a^{2} R^{2}+X_{C}^{2}}$

Where $R_{T}$ is the parallel resultant resistance due to $\mathrm{R}$ and $R_{D}$. Using admittance method of solving the circuit, the sum of admittances of the three branches of the circuit shown in Figure 4 must be zero, as no emf source or current source is present in the circuit.

$\overline{Y_{S}}+\overline{Y_{m}}+\overline{Y_{r}}=0$

Equating the real and imaginary part of (1) to zero, two nonlinear equations are obtained which are the function of per unit frequency a.

$\frac{\left(R_{L}+R_{1} / a\right)}{\left(X_{1}-X_{L}\right)^{2}+\left(R_{L}+R_{1} / a\right)^{2}}+\frac{R_{2} /(a-b)}{X_{2}^{2}+\left(R_{2} /(a-b)\right)^{2}}=0$

$-\frac{1}{X_{m}}-\frac{X_{2}}{X_{2}^{2}+\left(R_{2} /(a-b)\right)^{2}}-\frac{\left(X_{1}-X_{L}\right)}{\left(X_{1}-X_{L}\right)^{2}+\left(R_{L}+R_{1} / a\right)^{2}}=0$

Equation (2) and (3) may be solved to determine the unknown p.u. frequency i.e. 'a' and magnetizing reactance i.e. ' $\mathrm{X}_{\mathrm{m}}$ ' for given value of operating speed, excitation capacitance and load. 
Then, air gap voltage ' $E_{1}$ ' can be read using ' $X_{m}$ ' from the magnetization characteristics (Appendix-1)

The output voltage in terms of reduced frequency ' $a$ ' and air gap voltage ' $\mathrm{E}_{1}$ ' at rated frequency is given by:

$V=\frac{a E_{1}}{\left(\left[1-a^{2}\left(X_{1} / X_{C}\right)\right]^{2}+a^{2}\left[\left(X_{1} / R\right)^{2}+\left(R_{1} / X_{C}\right)^{2}\right]+\left[1+\left(R_{1} / R\right)\right]^{2}-1\right)^{1 / 2}}$

\section{STEADY STATE MODEL OF SEIG IN MATLAB/SIMULINK}

A new induction generator block for steady state analysis of SEIG has been developed as an embedded block in Matlab/Simulink wherein the output voltage of SEIG is obtained using equations (1-4). Input $R_{D}$ is obtained from switching system and is used for calculating current in the dump circuit i.e. $I_{D}$ and total resistance i.e. $R_{T}$. The model makes the process simple and more user friendly.

\section{SWITCHING SYSTEM}

To maintain constant terminal voltage, a switching system block has been developed in Matlab/Simulink. The switching system is shown in Figure 5. It is an embedded block in Matlab/Simulink which consists of thirteen branches in parallel, each consisting of resistive elements. An if-then-else block has been used in switching system which will decide which branch will have to be switched ON after ensuring load resistance $\mathrm{R}$ which is an input to this block. The output of this block will be dump resistance $R_{D}$ which will become as input to the induction generator block along with other inputs as shown in Figure 6. The switching system will provide a branch in parallel to load resistance in such a way so that total parallel combination of $R$ and $R_{D}$ is always a constant value.

The ladder diagram of resistances in parallel in switching system is shown in Figure 6.

As the input power is nearly constant, the output power of the SEIG must be held constant at all consumer loads. Any variation in consumer load will affect the terminal voltage and frequency. The aim of switching system has been that whenever there is variation in load, the switching system will switch ON a branch in such a way so as to maintain constant terminal voltage and hence the total power of SEIG remains equal to the rated power. As the consumer power decreases, the surplus power has been diverted in the dump load Thus, dump load has been connected in parallel to the consumer load in order to maintain the total power constant i.e.

$P_{G}=P_{C}+P_{D}$

\section{RESULTS AND DISCUSSIONS}

Figure 7 to Figure 10 shows the simulated results on test machine [Appendix-1] without switching system and Figure 11 to Figure 14 shows the simulated results on the same machine using switching control. As observed from Figure 8 and Figure 10, the terminal voltage and frequency varies with the change in load resistance i.e. when machine is unloaded whereas the simulated results for terminal voltage and frequency as shown in Figure 12 and Figure 14 are found to be well within the tolerable limits for any change in load resistance. This shows the effect of switching control on terminal voltage and frequency. The load resistance, terminal voltage, load current and time mentioned in Figure 7 to Figure 14 have their units ohms, volts, amperes and seconds respectively.

\section{CONCLUSION}

A new embedded block of Induction generator for steady state analysis along with switching system has been modeled and simulated in MATLABISIMULINK, for controlling the terminal voltage and frequency of SEIG under varying load conditions. It is observed that using Matlab/Simulink in steady state analysis of SEIG reduces not only the errors and lot of efforts in solving higher order polynomial equations: but, also makes it user friendly. It is also observed that switching system modeled gives an alternate way to control output voltage and frequency. It is a simpler method of control with resistive components resulting into reduction of the cost of the system.

\section{REFERENCES}

[1] Lahcene Quazene, George McPherson, "Analysis of the isolated induction generator," IEEE Transaction on PAS, Vol. PAS-102, No. 8, pp:2793-2798,August 1983.

[2] K.S.Sandhu, "Iterative Model for the analysis of selfexcited induction generators," Electric power components and systems, Vol.31,No.10, pp: 925-939, Oct.2003.

[3] S.Rajakaruna, R.Bonert, "Self-excited Induction generator with excellent voltage and frequency control," IEE Proc.-Gener. Transm. Distrib., Vol. 145, No.1, pp. 33-39, 1998.

[4] Bhim Singh, S.S.Murthy 2006. A steady state analysis on voltage and frequency control of self-excited induction generator in micro- hydro system. In proceedings IEEE International Conf. on Power Electronics Drives \& Energy Systems.

[5] G. Raina, O.P.Malik, "Wind energy conversion using self-excited induction generator," IEEE Trans., Power App. Syst., Vol. PAS-102,no.12, pp.3933-3936, Dec. 1983.

[6] S.S.Murthy, O.P Malik and A.K.Tandon, "Analysis of self excited inductiontor," Proc. Inst. Elect. Eng. C, Vol. 129, no.6, pp. 260-265,Nov. 1982.

[7] T.F.Chan, "Self-excited induction generators driven by regulated and unregulated turbines," IEEE Trans. Energy Convers., Vol. 11, no. 2, pp. 338-343, Jun. 1996.

[8] T.F.Chan, " Steady state analysis of self-excited induction generators," IEEE Trans. Energy Convers., vol. 9, no. 2, pp. 288-296, Jun. 1994.

[9] K.S.Sandhu, S.K.Jain, "Operational aspects of selfexcited induction generator using novel method," Elect. Mach. Power Syst., Vol 27, pp. 169-180, 1998.

[10] N.H. Malik and A.A. Mazi, " Capacitance requirements for isolated self excited induction generators," IEEE trans. on Energy Conversion, Vol. EC-2, No. 1, pp 6268, March 1987.

[11] Swati Devabhaktuni, S.V.Jayaram kumar, "Performance Analysis of wind turbine driven self-excited induction generator with external rotor capacitance," International Journal of advanced engineering science and technologies, Vol. 10, No. 1, pp. 1-6., 2011.

[12] Bhim Singh, S.S.Murthy, et.al 2003. Field experience on a novel pico-hydel system using self-excited induction generator and electronic load controller. In the Fifth International Conference PEDS .

[13] B.Singh, S.S.Murthy and S.Gupta 2004. Analysis and implementation of an electronic load controller for a self excited induction generator. In IEE Proceedings, Generation Transmission and Distribution.

[14] Bhim Singh, S.S.Murthy, Sushma Gupta, "Analysis and Design of electronic load controller for self -excited induction generators," IEEE Transactions on Energy conversion, Vol.21, No.1, pp.285-93, 2006. 


\section{Appendix-1}

\section{Details of Machine}

- Specifications

3phase, 4 pole, $50 \mathrm{~Hz}$, delta-connected, squirrel

cage induction machine $2.2 \mathrm{~kW} / 3.0 \mathrm{hp}, 230 \mathrm{~V}, 8.6 \mathrm{~A}$

\section{- Parameters}

$\mathrm{R}_{1}=3.35 \mathrm{ohm}, \mathrm{R}_{2}=1.76 \mathrm{ohm}, \mathrm{X}_{1}=\mathrm{X}_{2}=4.85 \mathrm{ohm}$

- Base Values

Base current $=4.96 \mathrm{~A}$, Base speed $=1500 \mathrm{rpm}$

- Air gap voltage

The piecewise linearization of magnetization characteristics of the machine gives

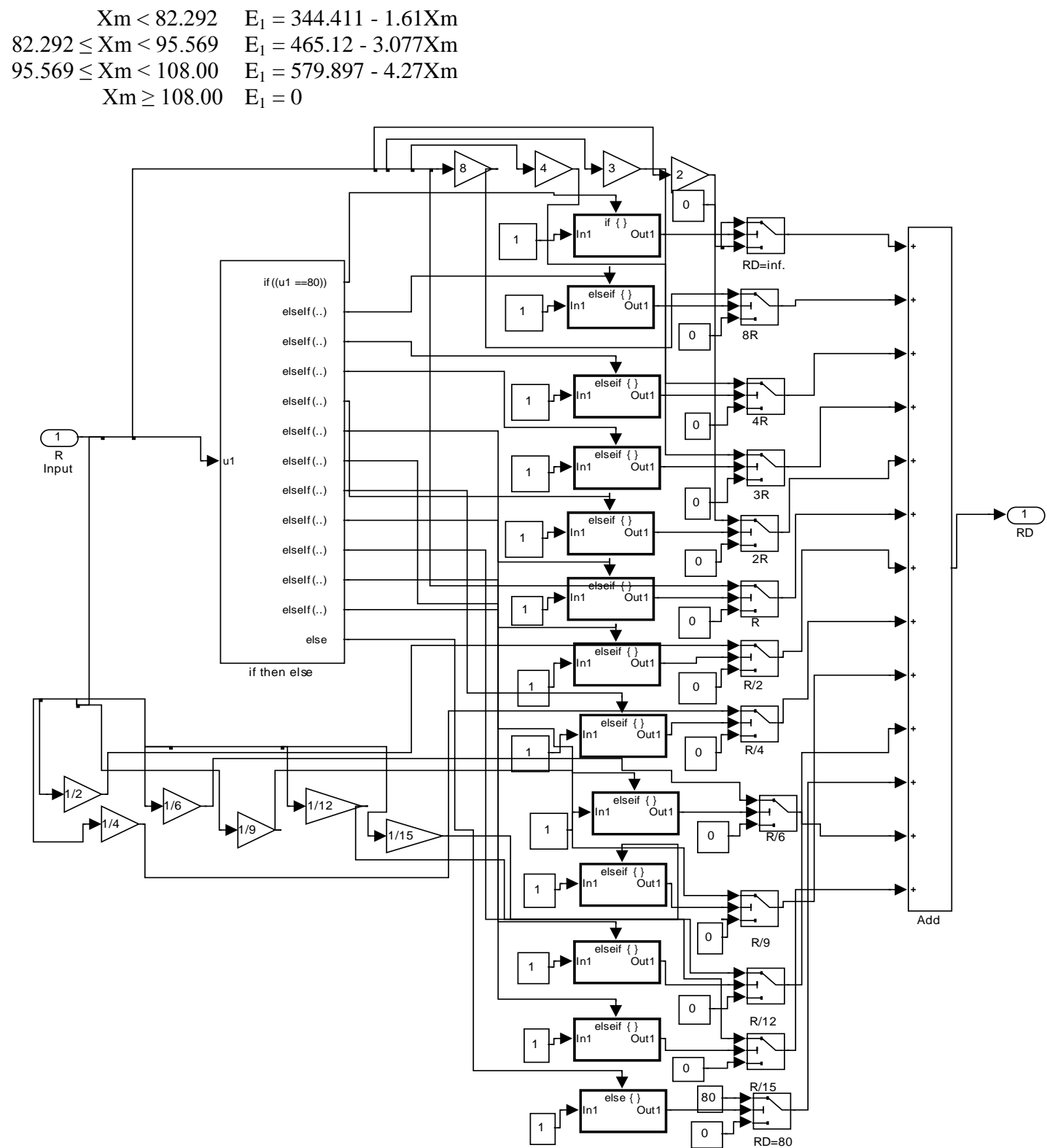

Fig.5: Switching system 


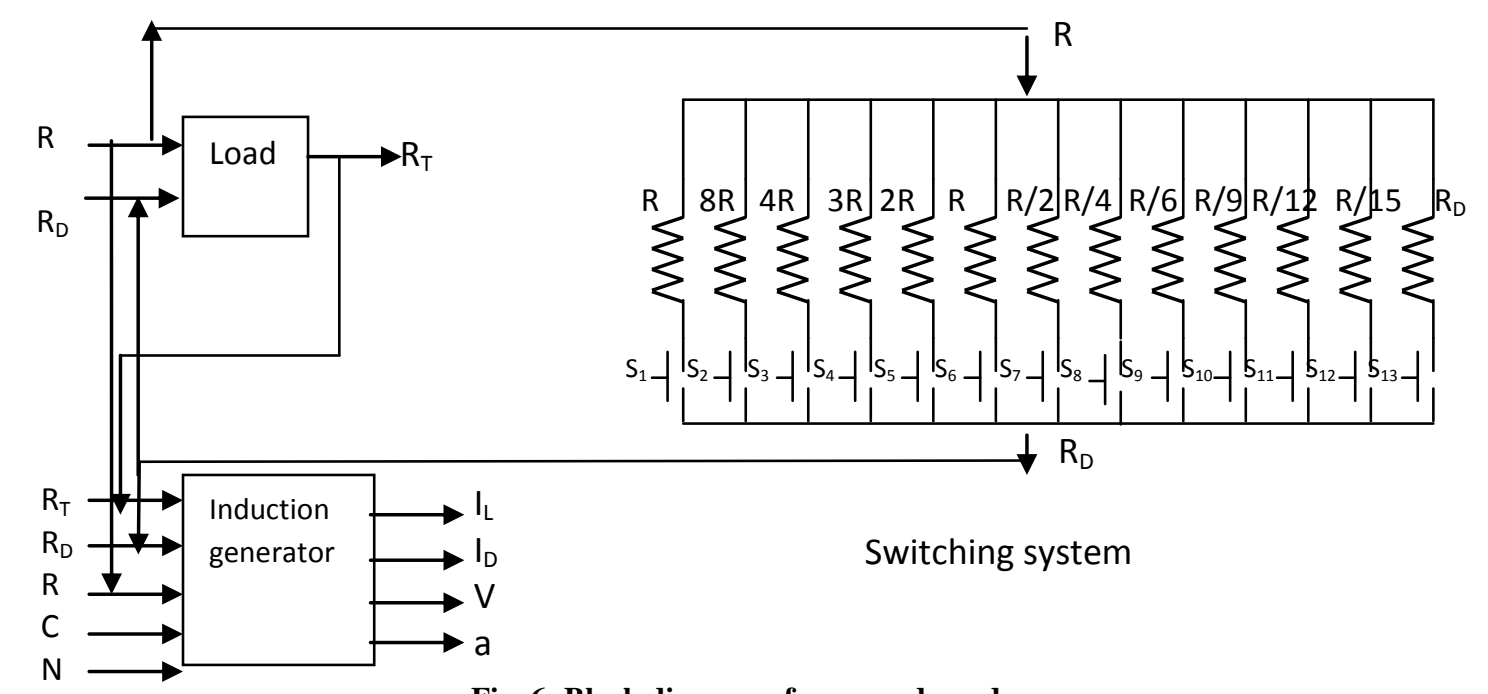

Fig. 6: Block diagram of proposed mode

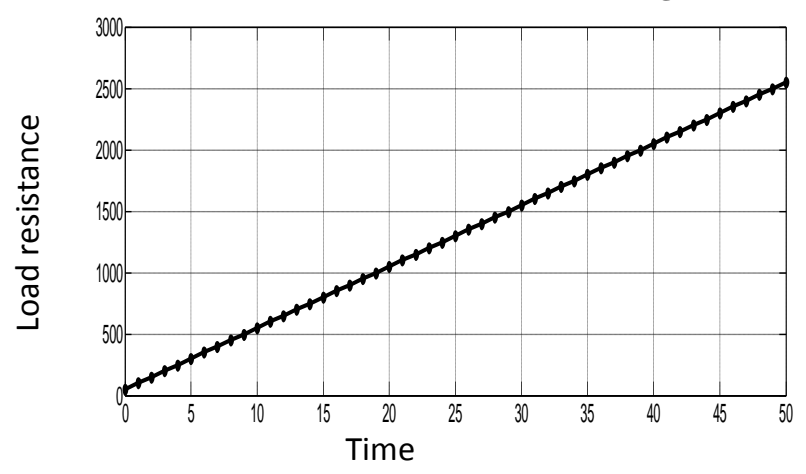

Fig.7: Load resistance variation with time

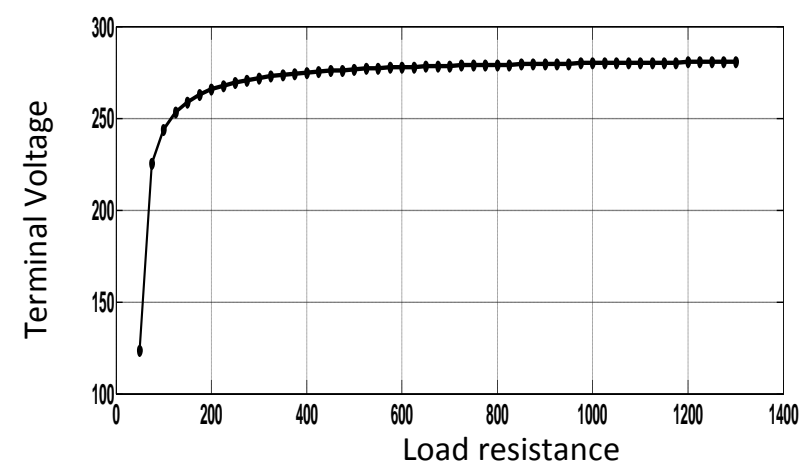

Fig. 8: Effect of load on output voltage

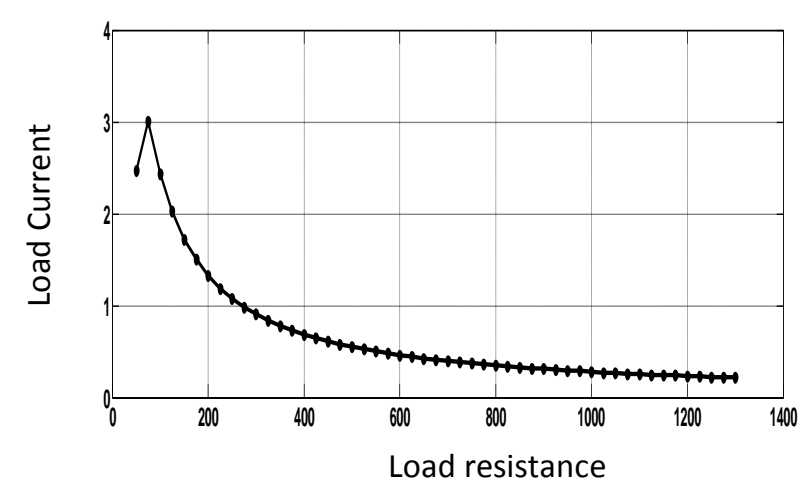

Fig. 9: Variation of load current

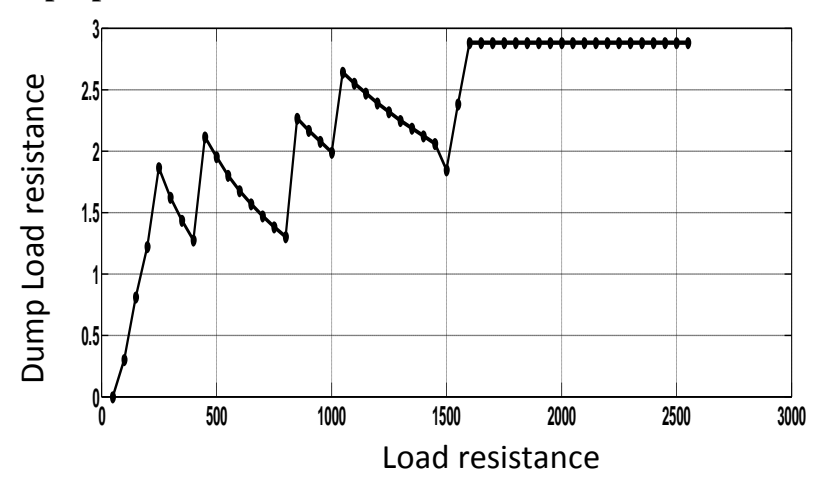

Fig.11: Variation in dump current with load

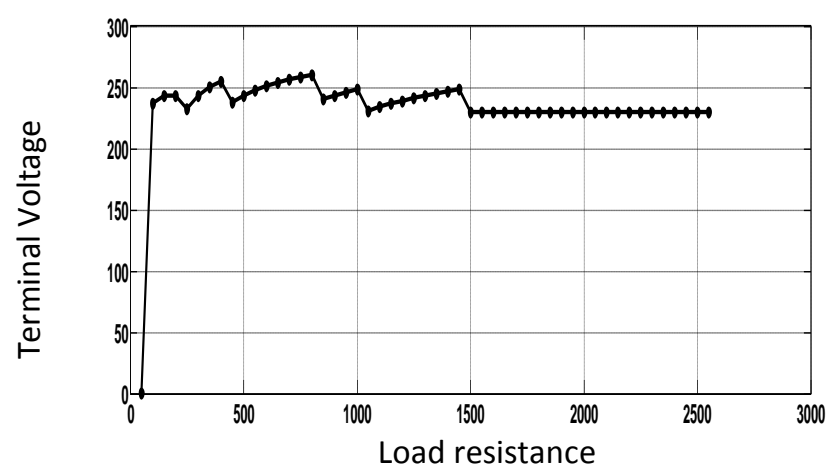

Fig. 12: Variation in terminal voltage with switching control

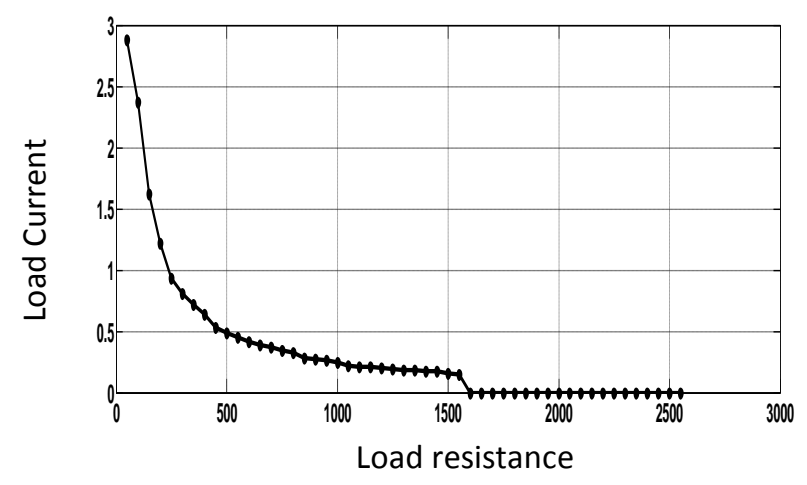




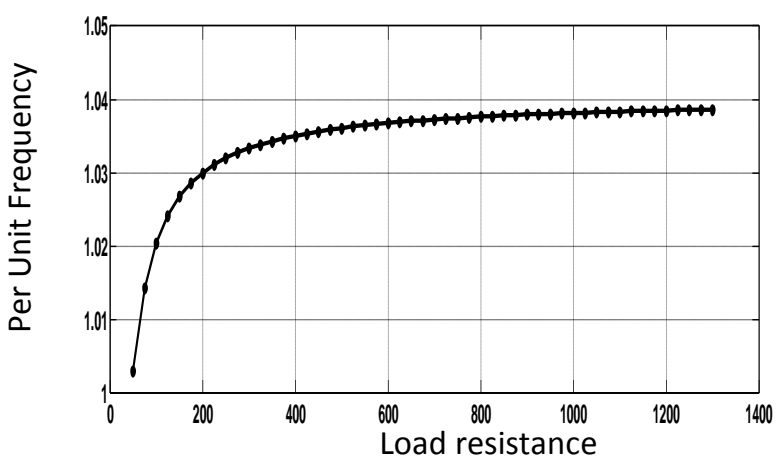

Fig. 10: Variation of frequency with load
Fig. 13: Variation in load current with switching control

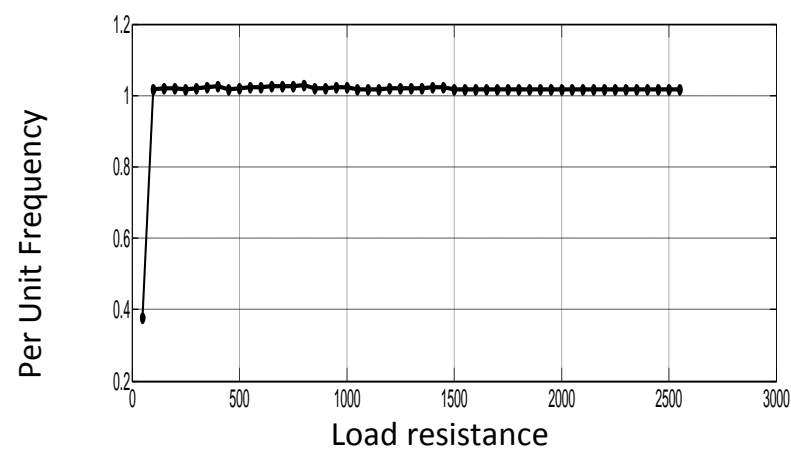

Fig. 14: Variation of generated frequency with switching control 